\title{
BMJ Open Impact of US smoke-free air laws on restaurants and bars by employer size: a panel study
}

\author{
Paul Shafer ${ }^{1,2}$
}

To cite: Shafer P. Impact of US smoke-free air laws on restaurants and bars by employer size: a panel study. BMJ Open 2017;7:e018137. doi:10.1136/ bmjopen-2017-018137

- Prepublication history and additional material for this paper are available online. To view these files, please visit the journal online (http://dx.doi. org/10.1136/bmjopen-2017018137).

Received 8 June 2017 Revised 23 September 2017 Accepted 23 October 2017

\section{CrossMark}

\section{${ }^{1}$ Department of Health Policy} and Management, Gillings School of Global Public Health, University of North Carolina, Chapel Hill, North Carolina, USA ${ }^{2}$ Center for Health Policy Science and Tobacco Research, RTI International, Research Triangle, North Carolina, USA

Correspondence to

Mr Paul Shafer;

pshafer@unc.edu

\begin{abstract}
Objectives Thirty states have smoke-free air laws that ban smoking in restaurants and bars, covering nearly two-thirds of the US population. It is well established that these laws generally have a null or positive economic impact on restaurants and bars. However, all establishments in a geographic area are usually treated as a homogeneous group without considering the potential for differential effects by establishment characteristics. This study uses variation in smoke-free air laws over time to estimate their impact on employment in restaurants and bars with a focus on potential differences by employer size (number of employees). A two-pronged approach with a national-level and state-level analysis is used to take advantage of more granular data availability for a single state (North Carolina).

Design Observational study using panel data.

Setting 1) US, 2) North Carolina

Interventions Smoke-free air laws.

Outcome measures State-level accommodation and food services employment for all 50 states and District of Columbia from 1990 through 2014 (Quarterly Census of Employment and Wages); county-level restaurant and bar employment in North Carolina from 2001 through 2014 (North Carolina Department of Commerce).

Results There is no evidence of a redistributive effect of smoke-free air laws on restaurant and bar employment by employer size.

Conclusion The lack of a redistributive effect is an important finding for policy-makers considering implementation or expansion of a smoke-free air law to protect employees and patrons from the dangers of exposure to secondhand smoke.
\end{abstract}

\section{INTRODUCTION}

Secondhand smoke exposure is responsible for an estimated 50000 deaths per year in the US among non-smoking adults and children. Smoke-free air laws in the US and abroad have been associated with drastic improvements in air quality and population health as well as decreases in smoking prevalence, ${ }^{1-6}$ an indication that reducing opportunities for social smoking may help encourage cessation and depress initiation by denormalising smoking in public. ${ }^{7}$ Thirty states currently have smokefree air laws that ban smoking in all restaurants

\section{Strengths and limitations of this study}

The potential for differential economic effects of smoke-free air laws by employer size is an understudied issue.

- This study uses panel data over a long time period, both at the national level (by state, 1990 through 2014) and for North Carolina (by county, 2001 through 2014), to provide a two-pronged examination of this question.

- Complementary statistical approaches were used to ensure that the choice of estimator does not bias the conclusions of the study.

- Data availability by employer size is quite poor for more specific business types (eg, restaurants and bars).

- Attenuation bias is a concern in the national analysis because it uses a higher aggregation of employment (accommodation and food services) than the target of the intervention (smoke-free air laws in restaurants and bars).

and bars, covering nearly two-thirds $(65.7 \%)$ of the US population. ${ }^{8}$ An additional five states have smoke-free air laws covering only restaurants, representing more than a tenth of the population (12.0\%). ${ }^{8}$ Despite the rapid expansion of smoke-free air laws during the 2000 s, ${ }^{9}$ strong public support ${ }^{1011}$ and a near consensus among peer-reviewed studies that smoke-free air laws have generally null or positive economic effects, ${ }^{12}$ legislative progress on this issue has stalled in recent years and even regressed in some cases. ${ }^{13}$ Population coverage by comprehensive smokefree air laws has barely changed since 2010 and perhaps counter-intuitively, states with pre-existing non-comprehensive laws are less likely to subsequently pass a more comprehensive law in the future. ${ }^{14-16}$ Exemptions in non-comprehensive laws have allowed establishments to reintroduce smoking, ${ }^{17}$ which is concerning given the disparities that already exist in workplace secondhand smoke exposure. $^{11}$ 
Opponents of these laws frequently claim that their implementation will have an adverse economic impact on the hospitality industry, particularly restaurants and bars, despite a strong evidence base to contradict these claims. Numerous studies have found generally null or positive effects of smoke-free air laws on either employment and/ or sales-the primary indicators used to measure the economic impact of these laws ${ }^{12}$-in restaurants and/or bars across the US. ${ }^{2-5} 12$ 18-29 A study using business sales found no evidence that smoke-free air laws impacted the value for which individual bars were sold after controlling for employer size, providing an indication that these laws do not differentially impact profitability. ${ }^{30}$ Several studies have found negative effects but the majority were not peer-reviewed and/or were supported by funding from the tobacco industry. ${ }^{12} 3132$

Prior studies of the economic impact of smoke-free air laws have examined their effect on employment and/or sales in aggregate for a given locality in which all restaurants and/or bars in a city are treated as a homogeneous group. This approach explicitly ignores the possibility that the effect on restaurants or bars might vary based on employer characteristics. Regulatory burdens have been found to disproportionately disadvantage smaller businesses and encourage larger firm size. ${ }^{33} 34$ Though smoke-free air laws may not create a cost burden, the potential for lost revenue from smoking clientele for an individual establishment can create a revenue burden. Since smaller establishments generally face a higher failure rate and may be more at risk from any sizeable loss of revenue, ${ }^{35}$ understanding whether prior estimates of generally null or positive effects may mask differential effects by employer size is an important gap to address. This study seeks to address this gap using a two-pronged approach: (1) a national analysis using 25 years of hospitality employment data from all 50 states and DC and (2) a state-level analysis using 14 years of county-level restaurant and bar employment data from North Carolina.

\section{METHODS \\ Data}

Employment: national

For the national analysis, annual state-level accommodation and food services employment (North American Industry Classification System (NAICS) 72) by employer size were obtained from the Bureau of Labor Statistics Quarterly Census of Employment and Wages (QCEW) for all 50 states and the District of Columbia for 1990 through 2014. These data are derived from quarterly tax reports to state labour departments by all employers subject to unemployment insurance, covering approximately $98 \%$ of US employment. ${ }^{36}$ Total accommodation and food services employment in each state-year was split into nine categories by employer size $(<5,5-9,10-19,20-49,50-99$, 100-249, 250-499, 500-999 and $\geq 1000$ employees). Any values suppressed to protect employer confidentiality were coded as missing and excluded from the analysis.
These data have been used in several prior studies of the economic impact of smoke-free air laws. ${ }^{20} 2737$

Restaurant and bar-specific data by employer size was not available. The QCEW only contains employment totals by employer size category at the state and two-digit NAICS industry code level for the first quarter of each year. Since the federal data are a product of data aggregated from state labour departments, the labour market information website for each state was identified and searched for more detailed data by employer size. Data availability by state is described in online supplementary appendix table A1 with a URL for the relevant labour market data web page, geographic level, NAICS code level and time period. Only three states (California, North Carolina and Washington) had data available that was better than what was available in the QCEW; however, California and Washington only had data available for years after their statewide smoke-free air laws had already gone into effect. The North Carolina data by employer size contained much greater geographical (county), industry (four-digit NAICS code) and temporal (quarter) detail than the QCEW (state, two-digit NAICS code, year), providing an opportunity to conduct a state-specific analysis for North Carolina to further inform this research question.

\section{Employment: North Carolina}

For the North Carolina analysis, quarterly employment data for restaurants (NAICS 7221 for 2001-2010, 7225 for 2011-2014) and bars (NAICS 7224) by employer size were obtained from the North Carolina Department of Commerce for all 100 counties for 2001 through 2014. The change in restaurant industry code was a result of adoption of changes to the underlying NAICS code structure by the state. ${ }^{38}$ Total restaurant and bar employment in each county quarter was split into nine categories by employer size $(<5,5-9,10-19,20-49,50-99,100-249$, 250-499, 500-999 and $\geq 1000$ employees). Any values suppressed to protect employer confidentiality were coded as missing and excluded from the analysis. Restaurant and bar employment within each employer size category were summed for the North Carolina analysis as spillover of employees between business types is not relevant to our analysis and the state-wide smoke-free air law covered both settings on implementation.

\section{Policy variables}

For the national analysis, the smoke-free air law policy variable is coded as a continuous variable measuring the percentage of each state's population covered by any (restaurant, bar, workplace) smoke-free air law (scaled from 0 to 100). If any counties or municipalities within a state adopt a smoke-free air law during the study period (1990-2014), this variable measures the percentage of the population accounted for by those areas of the state over time. When a state-wide smoke-free air law goes into effect, the smoke-free law variable is set equal to 100 beginning in that year. The QCEW data correspond to the first quarter of each year and were matched to state-level 
smoke-free air law coverage as of the beginning of that quarter. For the North Carolina analysis, the smoke-free air law policy variable is an indicator equal to 1 beginning in the first quarter of 2010 onward and 0 otherwise. These variables were derived from a chronological database of smoke-free air laws published by the American Nonsmokers' Rights Foundation and annual state population data from the US Census Bureau Population Estimates Program. ${ }^{9} 39$

\section{Covariates: national}

Annual state population data for 1990 through 2014 was obtained from the US Census Bureau Population Estimates Program. ${ }^{39}$ Annual state per capita pack sales for 1990 through 2014 were derived from pack sales data published in The Tax Burden on Tobacco and the preceding population estimates. ${ }^{40}$ Annual federal and state cigarette excise taxes for 1990 through 2014 were also obtained from The Tax Burden on Tobacco. Annual state non-hospitality employment was derived from the QCEW data by subtracting accommodation and food services employment from total employment for each state-year.

\section{Covariates: North Carolina}

Annual county-level population data in North Carolina for 2001-2014 was obtained from the CDC WONDER Bridged-Race Resident Population Estimates. ${ }^{41}$ Annual county-level adult smoking prevalence for 2001-2012 was obtained from small area Behavioral Risk Factor Surveillance System (BRFSS) estimates published by Dwyer-Lindgren et al. ${ }^{42}$ Quarterly county-level non-hospitality employment was derived from the QCEW data by subtracting accommodation and food services employment from total employment for each county-quarter.

\section{Statistical analysis}

Dynamic panel data models are used to estimate the relationship between smoke-free air laws and employment within each category of employer size. Two variations on a standard fixed effects model with an autoregressive term are used to estimate these policy effects: (1) an instrumental variable (IV) panel model and (2) a bias-corrected least squares dummy variable model (LSDVc). Such models are appropriate because they can account for the autoregressive nature of employment while also accounting for correlation of errors within groups, like states or counties, over time. The former approach (IV) has been used in two recent studies of the economic impact of smoke-free air laws and has the added advantage of accounting for simultaneity of changes in restaurant or bar employment and general economic activity. ${ }^{20}{ }^{27}$ The latter approach (LSDVc) reduces the bias inherent in an autoregressive fixed effects model without the efficiency losses of IV estimation. ${ }^{43-46}$

Employment in restaurants and bars exhibits a high degree of correlation between past and present values (0.95-0.99 across employer size categories in national data, 0.57-0.86 in North Carolina data). To account for the dynamic nature of employment, the lagged value of the outcome (autoregressive term) is included as a covariate. To account for general economic activity that may also affect restaurants and bars, independent of the implementation of smoke-free air laws, non-hospitality employment (in units of 10 000) is also included as a covariate in each model. Population was highly correlated with non-hospitality employment $(>0.9)$ and therefore not included as a covariate in the models. State cigarette pack sales per capita and real total cigarette excise taxes (federal plus state, in 2014 dollars) are included in the national analysis. County smoking prevalence is included in an alternate specification for North Carolina since it is only available through 2012, which results in the dropping of the final 2years of data from the model (2013-2014).

The IV models were estimated using xtivreg with the fixed-effects estimator and bootstrapped standard errors (100 replications). In these models, non-hospitality employment, for either the state-year or county-quarter level, was instrumented for by its lagged value to account for unobserved confounders that may simultaneously affect restaurant or bar employment and general economic activity. ${ }^{47}$ All first-stage F-statistics were significant at the 0.01 level. The LSDVc models were estimated using $x t l s d v c$ with bootstrapped standard errors (100 replications) ${ }^{43}$ In the national analysis, state fixed effects were included in all models to account for any unobserved differences between states. In the North Carolina analysis, county and quarter (January to March, April to June, July to September, October to December) fixed effects were included in all models to account for any unobserved differences between counties and potential seasonality in employment. All analyses were conducted using Stata V.14.2. ${ }^{48}$

\section{RESULTS}

The results presented below focus on employment in the employer size categories of fewer than 100 employees $(<5$, $5-9,10-19,20-49$ and 50-99). In 2014, $98.8 \%$ of restaurants and $99.8 \%$ of bars had fewer than 100 employees nationally. Results for the remaining categories (100-249, 250-499, 500-999 and $\geq 1000$ ) in the national analysis are presented in online supplementary appendix tables A2 and A3. For North Carolina, these models were not estimated due to an increasingly small number of counties with non-missing employment values (100-249: 24 counties (of 100), 250-499: 2, 500-999: 1, and $\geq 1000: 0$ ), which limits generalisability of the results back to the state level.

Tables 1 and 2 contain the regression results for the national analysis using the IV and LSDVc models, respectively. The percentage of state population covered by any smoke-free air law was not associated with state-level accommodation and food services employment in all but one case. In the IV models (table 1), percentage of state population covered by any smoke-free air law was only significantly associated with accommodation and food services employment for employers with five to nine 
Table 1 State accommodation and food services employment models, IV

State accommodation and food services employment by employer size category, b (SE)

<5 employees 5-9 employees 10-19 employees 20-49 employees 50-99 employees

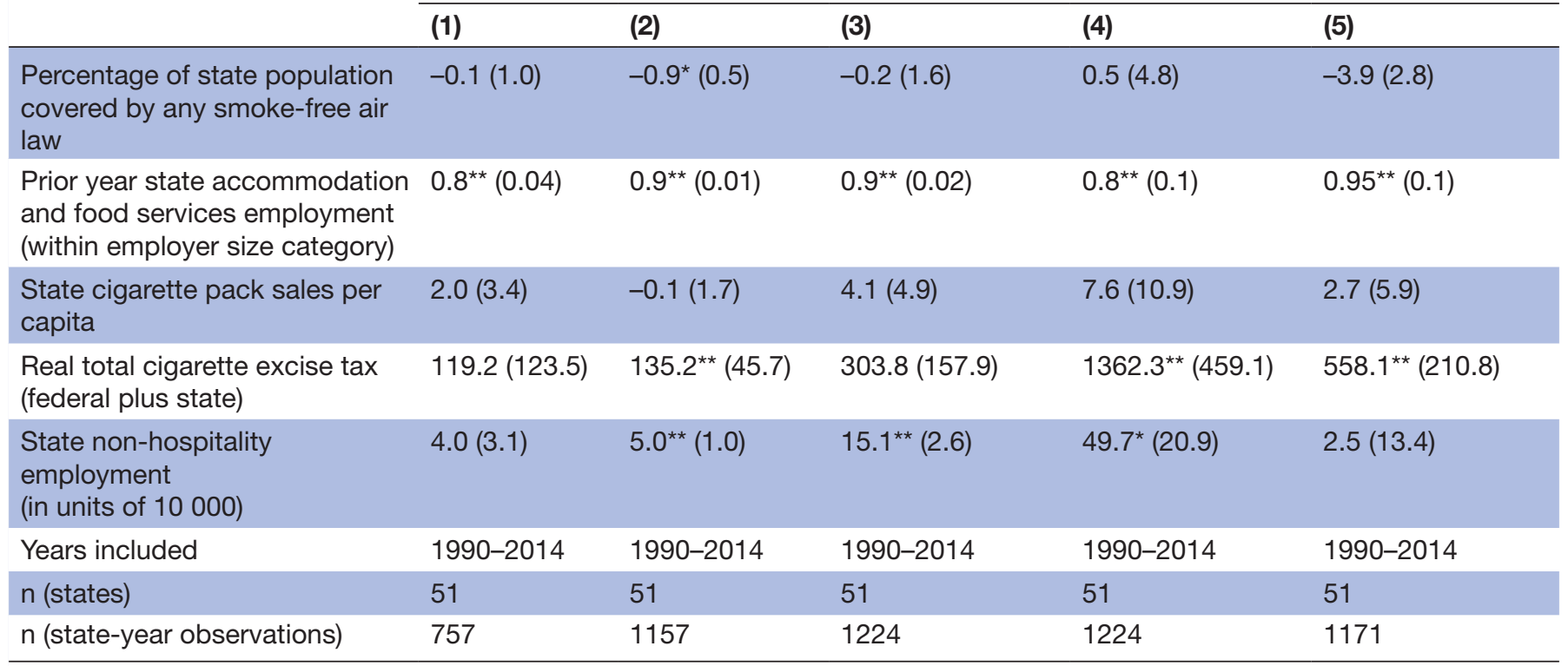

State non-hospitality employment instrumented for by its lagged value. State fixed effects not shown.

${ }^{*} \mathrm{P}<0.05 ;{ }^{* *} \mathrm{P}<0.01$.

IV, instrumental variable.

employees (model 2: $\mathrm{b}=-0.9, \mathrm{P}<0.05)$, indicating a decrease of approximately one hospitality employee per additional $1 \%$ of state population covered by a smoke-free air law within that employer size category. In the corresponding
LSDVc model (table 2), the estimated effect was of similar magnitude but not statistically significant (model 2: $\mathrm{b}=-$ $1.1, \mathrm{P}>0.05)$. Rising cigarette excise taxes were associated with increasing state accommodation and food services

Table 2 State accommodation and food services employment models, LSDVc

State accommodation and food services employment by employer size category, b (SE)

<5 employees 5-9 employees 10-19 employees 20-49 employees 50-99 employees

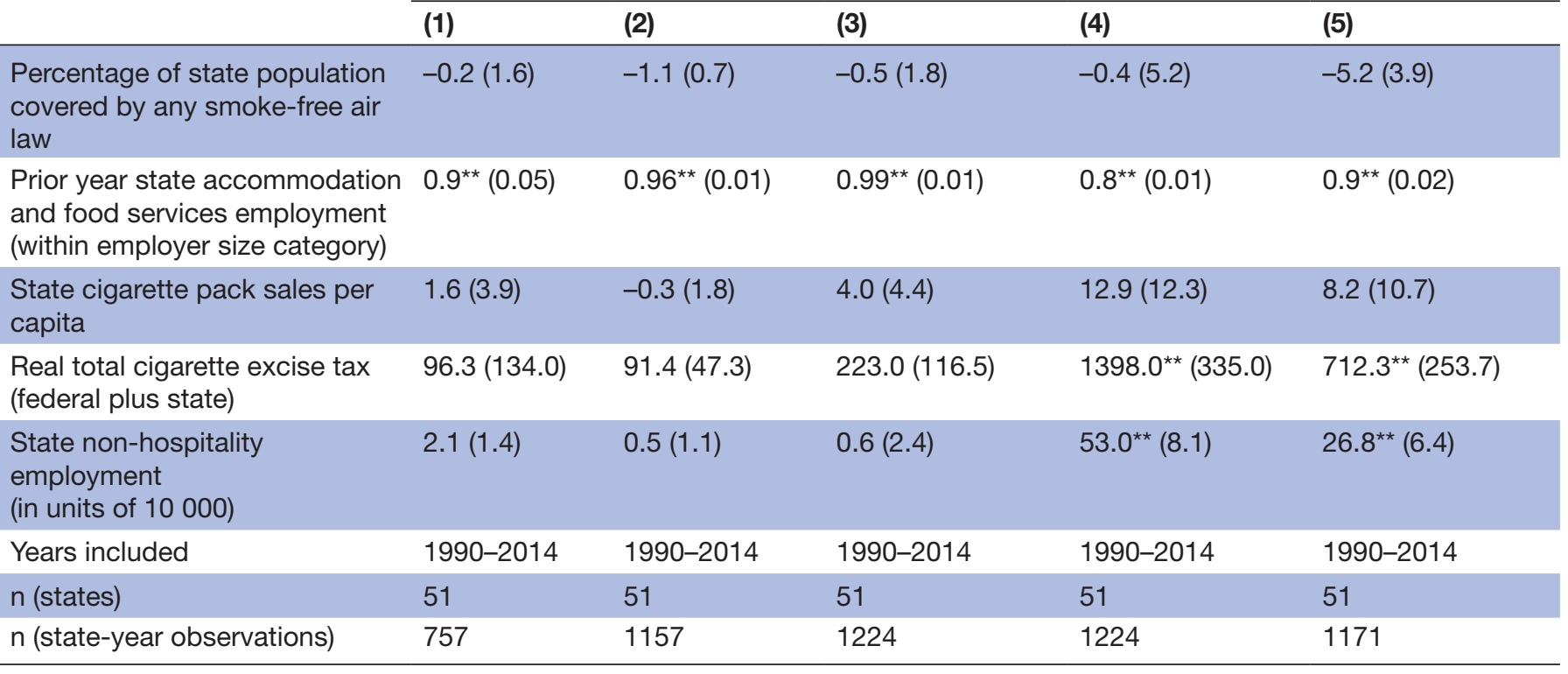

State fixed effects not shown.

${ }^{* *} \mathrm{P}<0.01$.

LSDVc, bias-corrected least squares dummy variable. 

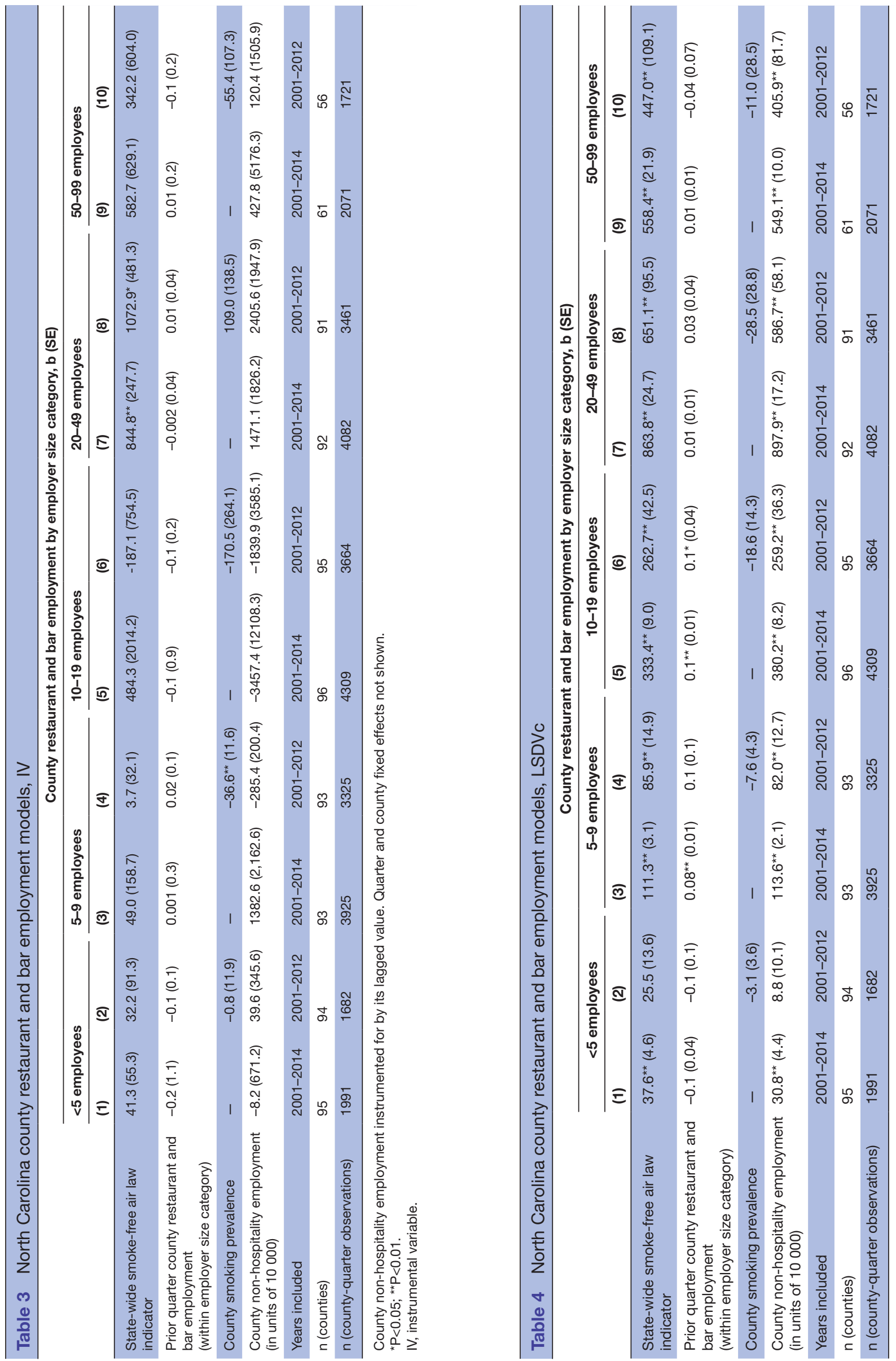
employment in 5 of 10 models (table 1, models 2, 4 and 5 ; table 2, models 4 and 5). An alternate specification that includes year fixed effects (not shown) yielded qualitatively similar findings.

Tables 3 and 4 contain the regression results for the North Carolina analysis using the IV and LSDVc models, respectively. The state-wide smoke-free air law indicator was either insignificant or indicated a positive effect on county-level restaurant and bar employment across all categories of employer size. In comparing the results between estimators, it is clear that LSDVc models (table 4) exhibited the expected improvements in efficiency (smaller standard errors) over the IV models (table 3). In the IV models (table 3), the state-wide smoke-free air law was only significantly associated with restaurant and bar employment for employers with 20-49 employees (model 7: $\mathrm{b}=844.8, \mathrm{P}<0.01$; model 8: $\mathrm{b}=1072.9, \mathrm{P}<0.05$ ), indicating an increase of approximately 800-1100 restaurant and bar employees per county attributable to the law within that employer size category. In the LSDVc models (table 4), the state-wide smoke-free air law was positively associated with restaurant and bar employment in all five employer size categories and 9 out of 10 models, with effect estimates ranging from an increase of nearly 40 employees per county in the $<5$ employees category (model 1: $\mathrm{b}=37.6, \mathrm{P}<0.01$ ) to more than 850 employees in the 20-49 employees category (model 7: $\mathrm{b}=863.8$, $\mathrm{P}<0.01)$. Increasing county smoking prevalence was associated with a decline in county restaurant and bar employment in one model (table 3, model 4).

\section{DISCUSSION}

These results suggest that smoke-free air laws have either a null or positive effect on restaurant and bar employment, consistent with extensive prior research. ${ }^{12} 1920232728$ In the North Carolina analysis, I find that increased smokefree air law coverage may be associated with increases in employment within some employer size categories, which echoes recent work indicating a potential rise in overall dining expenditures associated with smoke-free air laws. ${ }^{49}$ In the national analysis, there was a negative association within a single employer size category; however, its statistical significance was not consistent across estimators.

The strengths of this study include the novelty of estimating differential effects by employer size and employing complementary estimators to ensure that the conclusions are not overly influenced by the statistical methods used. Self-categorisation of business type is a limitation though one that is applicable to any study using employment or sales tax data. The national analysis is limited by its use of accommodation and food services employment as the outcome, which includes other types of workplaces besides restaurants and bars (eg, hotels and resorts), making it difficult to analyse smoke-free air laws that may impact only specific types of businesses (eg, non-comprehensive smoke-free air laws). As restaurant and bar employment only accounts for approximately $43 \%$ of accommodation and food services sector employment, attenuation bias is a likely problem. However, the North Carolina analysis provided an opportunity to corroborate the findings of the national analysis and directly address its limitations. The estimated effects are much larger in the single-state analysis, indicating that the national estimates were likely attenuated as expected.

These findings provide empirical evidence that there is no redistributive effect between smaller and larger establishments underlying generally null or positive estimates of the economic impact of smoke-free air laws-a potential concern for policy-makers seeking to balance the health of local businesses and public health. ${ }^{50}$ This is critical in light of recent work, highlighting disparities in employees' exposure to secondhand smoke and stagnation of legislative action in spite of strong public support for these laws. ${ }^{1113}$ The lack of a redistributive effect is an important finding for policy-makers considering implementation or expansion of a smoke-free air law to protect employees and patrons from the dangers of exposure to secondhand smoke.

Twitter@shaferpr

Competing interests None declared.

Provenance and peer review Not commissioned; externally peer reviewed.

Data sharing statement This study uses data assembled from several publicly available sources, including the Quarterly Census of Employment and Wages (Bureau of Labor Statistics, North Carolina Department of Commerce), Population Estimates Program (US Census Bureau), US Tobacco Control Laws Database (American Nonsmokers' Rights Foundation) and other publications with accompanying data. The analytic dataset and accompanying code are available from the author upon request for non-commercial research purposes.

Open Access This is an Open Access article distributed in accordance with the Creative Commons Attribution Non Commercial (CC BY-NC 4.0) license, which permits others to distribute, remix, adapt, build upon this work non-commercially, and license their derivative works on different terms, provided the original work is properly cited and the use is non-commercial. See: http://creativecommons.org/ licenses/by-nc/4.0/

(c) Article author(s) (or their employer(s) unless otherwise stated in the text of the article) 2017. All rights reserved. No commercial use is permitted unless otherwise expressly granted.

\section{REFERENCES}

1. U.S. Department of Health and Human Services. The health consequences of involuntary exposure to tobacco smoke: a report of the surgeon genera. Atlanta, Georgia, 2006.

2. Hahn EJ. Smokefree legislation: a review of health and economic outcomes research. Am J Prev Med 2010;39:S66-76.

3. Alpert HR, Carpenter CM, Travers MJ, et al. Environmental and economic evaluation of the Massachusetts Smoke-Free Workplace Law. J Community Health 2007;32:269-81.

4. Eriksen MP, Cerak RL. The diffusion and impact of clean indoor air laws. Annu Rev Public Health 2008;29:171-85.

5. Eriksen M, Chaloupka F. The economic impact of clean indoor air laws. CA Cancer J Clin 2007;57:367-78.

6. Hahn EJ, Rayens MK, Butler KM, et al. Smoke-free laws and adult smoking prevalence. Prev Med 2008;47:206-9.

7. Bayer R, Bachynski KE. Banning smoking in parks and on beaches: science, policy, and the politics of denormalization. Health Aff 2013;32:1291-8.

8. American Nonsmokers' Rights Foundation. Summary of $100 \%$ smokefree state laws and population protected by $100 \%$ U.S. Smokefree laws. http://no-smoke.org/pdf/SummaryUSPopList.pdf (accessed 23 Feb 2017). 
9. American Nonsmokers' Rights Foundation. Chronological table of U.S. population protected by $100 \%$ smoke-free state or local laws. $h$ ttp://no-smoke.org/pdf/EffectivePopulationList.pdf (accessed 23 Feb 2017).

10. Nagelhout GE, Wolfson T, Zhuang YL, et al. Population support before and after the implementation of smoke-free laws in the United States: trends from 1992-2007. Nicotine Tob Res 2015;17:350-5.

11. King BA, Homa DM, Dube SR, et al. Exposure to secondhand smoke and attitudes toward smoke-free workplaces among employed U.S. adults: findings from the National Adult Tobacco Survey. Nicotine Tob Res 2014;16:1307-18.

12. Cornelsen L, McGowan Y, Currie-Murphy LM, et al. Systematic review and meta-analysis of the economic impact of smoking bans in restaurants and bars. Addiction 2014;109:720-7.

13. Holmes CB, King BA, Babb SD. Stuck in neutral: stalled progress in statewide comprehensive smoke-free laws and cigarette excise taxes, united states, 2000-2014. Prev Chronic Dis 2016;13:E80.

14. Tynan MA, Holmes CB, Promoff G, et al. State and local comprehensive smoke-free laws for worksites, restaurants, and bars - united states, 2015. MMWR Morb Mortal Wkly Rep 2016;65:623-6.

15. Tung GJ, Vernick JS, Stuart EA, et al. Political factors affecting the enactment of state-level clean indoor air laws. Am J Public Health 2014:104:e92-7.

16. Sanders-Jackson A, Gonzalez M, Zerbe B, et al. The pattern of indoor smoking restriction law transitions, 1970-2009: laws are sticky. Am J Public Health 2013;103:e44-51.

17. Chandora RD, Whitney CF, Weaver SR, et al. Changes in Georgia restaurant and bar smoking policies from 2006 to 2012. Prev Chronic Dis 2015;12:E74.

18. Pyles MK, Hahn EJ. Economic effects of smoke-free laws on rural and urban counties in Kentucky and Ohio. Nicotine Tob Res $2012 ; 14: 111-5$

19. Klein EG, Forster JL, Collins NM, et al. Employment change for bars and restaurants following a statewide clean indoor air policy. $A m \mathrm{~J}$ Prev Med 2010;39:S16-22.

20. Shafer PR, Loomis BR. Economic impact of smoke-free air laws in north dakota on restaurants and bars. Nicotine Tob Res 2016;18:1798-801.

21. Boles M, Dilley J, Maher JE, et al. Smoke-free law associated with higher-than-expected taxable retail sales for bars and taverns in Washington State. Prev Chronic Dis 2010;7:A79.

22. Cowling DW, Bond P. Smoke-free laws and bar revenues in California-the last call. Health Econ 2005;14:1273-81.

23. Young WF, Szychowski J, Karp S, et al. Economic impacts of the Pueblo Smoke-Free Air Act. Am J Prev Med 2010;38:340-3.

24. Tauras JA, Chaloupka FJ, Keith JD, et al. Economic impact of a noncomprehensive smoke-free air law. Health Promot Pract 2014:15:521-9.

25. Collins NM, Shi Q, Forster JL, et al. Effects of clean indoor air laws on bar and restaurant revenue in Minnesota cities. Am J Prev Med 2010;39:S10-15

26. Kayani N, Cowan SR, Homan SG, et al. Economic effect of smokefree ordinances on 11 Missouri cities. Prev Chronic Dis 2012;9.

27. Loomis BR, Shafer PR, van Hasselt M. The economic impact of smoke-free laws on restaurants and bars in 9 States. Prev Chronic Dis 2013:10:E128.

28. Klein EG, Hood NE. The smoking ban next door: do hospitality businesses in border areas have reduced sales after a statewide smoke-free policy? Health Policy 2015;119:44-9.

29. Pyles MK, Hahn EJ. Economic effects of Ohio's smoke-free law on Kentucky and Ohio border counties. Tob Control 2011;20:73-6.
30. Alamar B, Glantz SA. Effect of smoke-free laws on bar value and profits. Am J Public Health 2007;97:1400-2.

31. Scollo M, Lal A, Hyland A, et al. Review of the quality of studies on the economic effects of smoke-free policies on the hospitality industry. Tob Control 2003;12:13-20.

32. Scollo M, Lal A. Summary of studies assessing the economic impact of smokefree policies in the hospitality industry. $2008 \mathrm{http} / / / \mathrm{www}$. webcitation.org/6LcMsGfS9 (accessed 22 Sep 2017).

33. Administration SB. The Impact of Regulatory Costs on Small Firms, 2010.

34. Calcagno PT, Sobel RS. Regulatory costs on entrepreneurship and establishment employment size. Small Business Economics 2014;42:541-59.

35. Dhawan R. Firm size and productivity differential: theory and evidence from a panel of US firms. J Econ Behav Organ 2001;44:269-93.

36. U.S. Department of Labor, Bureau of Labor Statistics. Quarterly Census of Employment and Wages. http://www.bls.gov/cew/ (accessed 1 Jul 2016)

37. Adams S, Cotti CD. The effect of smoking bans on bars and restaurants: an analysis of changes in employment. $B E \mathrm{~J}$ Econom Anal Policy 2007; 7

38. U.S. Department of Labor, Bureau of Labor Statistics. Notice of series changes with the update to North American IndustryClassification System 2012 and Annual Benchmark Release on February 3, 2012. http://www.bls.gov/ces/cesnaics12.htm (accessed 1 Jul 2016).

39. U.S. Census Bureau. Population and housing unit estimates. http:// www.census.gov/popest/index.html (accessed 23 Feb 2017).

40. Orzechowski and Walker. The Tax Burden on Tobacco: Historical Compilation, Volume 49. Arlington, Virginia, 2014.

41. U.S. Department of Health and Human Services, Centers for DiseaseControl and Prevention. Bridged-Race Resident Population Estimates, United States, State and County for the years 1990 - 2015. http://wonder.cdc.gov/wonder/help/bridged-race.html (accessed 1 Jul 2016).

42. Dwyer-Lindgren L, Mokdad AH, Srebotnjak T, et al. Cigarette smoking prevalence in US counties: 1996-2012. Popul Health Metr 2014;12:5.

43. XTLSDVC: Stata module to estimate bias corrected LSDV dynamic panel data models. Version S450101 Boston College Department of Economics. 2005.

44. Bruno GSF. Approximating the bias of the LSDV estimator for dynamic unbalanced panel data models. Econ Lett 2005;87:361-6.

45. Bruno GSF. Estimation and inference in dynamic unbalanced panel data models with a small number of individuals. Stata Journal 2005:5:473-500.

46. Judson RA, Owen AL. Estimating dynamic panel data models: a guide for macroeconomists. Econ Lett 1999;65:9-15.

47. Baum CF, Schaffer ME, Stillman S. Enhanced routines for instrumental variables/generalized methods of moments estimation and testing. Stata Journal 2007;7:465-506.

48. Stata Statistical Software: Release 14 [computer program]. College Station, TX: StataCorp LP. 2015

49. Kim D, Yörük BK. The impact of restaurant smoking bans on dining out expenditures: Evidence from panel data. J Urban Econ 2015;88:38-49.

50. York NL, Pritsos CA, Gutierrez AP. Legislators' beliefs on tobacco control policies in Nevada. J Community Health 2012;37:89-95. 